Proceedings of the International School and Conference on Optics and Optical Materials, ISCOM07, Belgrade, Serbia, September 3-7, 2007

\title{
Luminescence of Lanthanides from Xerogels Embedded in Mesoporous Matrices
}

\author{
N.V. Gaponenko* \\ Laboratory of Nanophotonics \\ Belarusian State University of Informatics and Radioelectronics \\ Browki St. 6, 220013 Minsk, Belarus
}

\begin{abstract}
The report summarizes peculiarities of synthesis and luminescence properties of porous silicon, porous anodic alumina and artificial opals with the inclusions of sol-gel derived oxides (xerogels), doped with Er, Tb, and Eu. Origin of strong luminescence of lanthanides from xerogels in mesoporous matrices is discussed.

PACS numbers: 81.20.Fw, 83.80.Jx, 81.05.Rm, 78.55.Mb, 61.43.Gt, 82.45.Cc, 42.70.Qs, 78.55.Ap, 78.60.-b
\end{abstract}

\section{Introduction}

Interest in sol-gel synthesis arises from the relatively low cost and the approach allows the chemical content and concentration ratio of the elements of the sol-gel derived films to be tailored, with ready fabrication in a form of powder, thin films, and bulk materials. Sol-gel derived materials could be prepared from a colloidal solution which is a dispersion of colloidal particles with diameter of $1-100 \mathrm{~nm}$ in a liquid [1].

About a decade ago it was demonstrated that colloidal solutions deposited by spinning are able to penetrate through the channels of mesoporous matrices, enabling after heat treatment the fabrication of a xerogel (dried gel) located within the porous layer of several micrometers thickness. Most of the experiments with this property of sol-gel synthesis have been done with mesoporous materials as porous silicon, porous anodic alumina (PAA) and artificial opals. Since properties of these porous materials themselves in recent years are intensively studied giving sometimes fascinating results, it might be reasonable to summarize some works with these porous materials, containing diverse xerogel inclusions inside. To our knowledge, synthesis of sol-gel derived oxides in mesoporous materials was started from porous silicon.

*corresponding author; e-mail: nik@nano.bsuir.edu.by 


\section{Porous silicon}

Fabrication of porous silicon still remains one of the most simple methods of synthesis porous material due to silicon ability to oxidize or dissolve [2]. Type of porosity of this material depends on the doping level of silicon substrate, the current density and concentration of electrolyte, usually, HF-solution; thus micro-, meso-, and macroporous silicon could be fabricated using the same electrochemical cell [3]. Although porous silicon had been investigated in microelectronics since 1950s [4, 5], a burst of interest to it occurred in 1990 when luminescent properties of porous $\mathrm{Si}$ were reported [6]. Interest in fabrication of the structure xerogel/porous silicon was initiated in 1990 s by a challenging problem of development light-emitting devices for visible and infrared emission on silicon basis. In the experiments micro- [7], meso- [8-14], and macroporous [15] silicon was used for spin-on deposition of coatable sols containing erbium nitride dissolved in water and ethanol. $\mathrm{Si}\left(\mathrm{OC}_{2} \mathrm{H}_{5}\right)_{4}$ and $\mathrm{Fe}(\mathrm{OH})_{3}$ were used as the precursors. Penetration of the sols through the channel of the pores was concluded from observation the components of xerogels with secondary-ion mass spectroscopy (SIMS) and secondary-neutral mass spectroscopy (SNMS) [8, 9], cross-section TEM-images [13], and Rutherford backscattering (RBS) [12] in porous silicon 0.3 [13], 1.5 [12], and $5[8] \mu \mathrm{m}$ thick.

We have to clarify that considering the structure xerogel:lanthanide ion/porous silicon, subjected to heat treatment, luminescence of lanthanides could be observed either from xerogel or from porous silicon. Luminescence of lanthanide ion from porous silicon needs greater annealing temperature than from xerogel. Thus $\mathrm{Tb}$ luminescence from $\mathrm{SnO}_{2}$ xerogels was observed after annealing at $500^{\circ} \mathrm{C}$ and was associated with $\mathrm{Tb}^{3+}$ in $\mathrm{SnO}_{2}$ casseterites located in the channels of the pores of porous silicon [13], whereas annealing even above $700^{\circ} \mathrm{C}$ did not prove any energy transfer from porous silicon to $\mathrm{Tb}$, revealing at the same time strong $\mathrm{Tb}$ luminescence [16]. Erbium luminescence from porous silicon was well resolved at room temperature after annealing within the temperature range $300-600^{\circ} \mathrm{C}$ in sol-gel derived $\mathrm{In}_{2} \mathrm{O}_{3}$ film [11], that is much lower than needed for erbium-implanted porous silicon [17] and other solids [18] or electrochemically doped porous silicon $[19,20]$. Er photoluminescence (PL) from the structure silicagel/porous silicon is strongly dependent on annealing conditions (temperature and atmosphere) and could be varied within 5 orders of magnitude [12].

As was reported by two groups independently [8, 12], after removing the oxides from erbium-doped silicagel/porous silicon structure in HF-solution, the erbium-related luminescence disappeared, but it was restored again by the next high-temperature annealing. Although diffusion doping of porous silicon, particularly its crystalline phase, with lanthanides needs high-temperature annealing and should be confirmed with high-resolution excitation spectroscopy [7, 21], we have to admit that the structure xerogel, doped with lanthanide ion / mesoporous silicon exhibit strong room-temperature luminescence of lanthanides (Fig. 1). For 
example, erbium-doped silicagel/porous silicon structure $1.5 \mu \mathrm{m}$ thick with the ratio of elements $\mathrm{Er} / \mathrm{Si}=3 \times 10^{-3}$ exhibit erbium-related room-temperature $\mathrm{PL}$ about two orders of magnitude greater than from similar porous silicon implanted with a dose $10^{15} \mathrm{~cm}^{-2}$ of erbium [12].

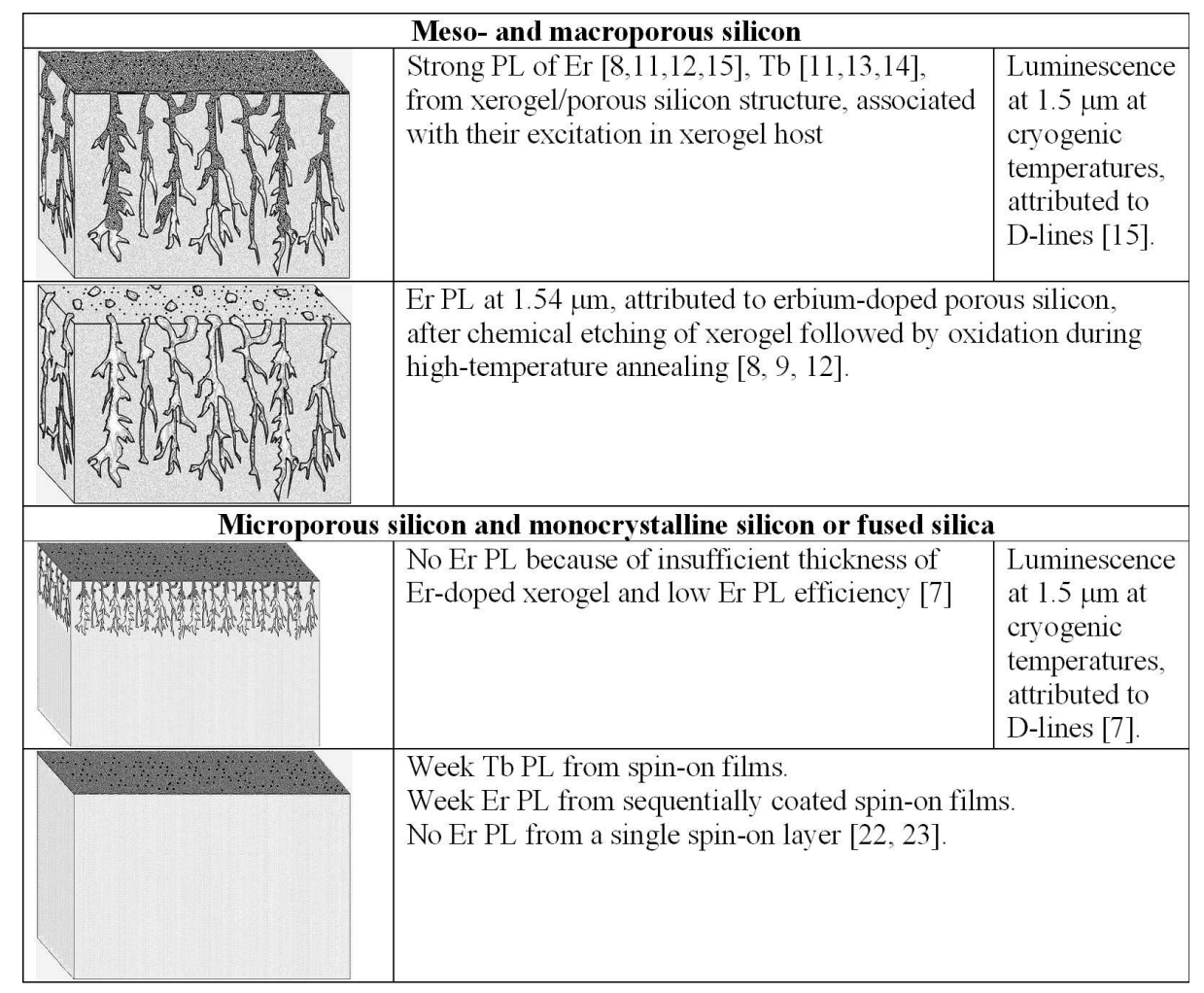

Fig. 1. Schematic illustration of xerogels doped with Er or Tb on monocrystalline and different kinds of porous silicon.

However, if diameter of the pores is insufficient for penetration the sols through the channels of the pores, like for microporous silicon, pore size $<10 \mathrm{~nm}$, only a thin spin-on film could be fabricated on the surface of the sample (Fig. 1). In this case luminescence of lanthanides from the fabricated single spin-on xerogel layer is very weak like for ordinary thin spin-on films on flat non-porous substrates from silicon or silica $[22,23]$ and, especially for erbium, needs relatively high excitation power to be detected at room temperature. PL at $1.5 \mu \mathrm{m}$ observed at cryogenic temperatures (below $160 \mathrm{~K}$ [7]) from spin-on films on microporous silicon is associated with $D$-series of dislocation lines [15, 24].

Besides strong PL of lanthanides from xerogel/mesoporous silicon, ability of optical modification of the voids of the pores by tuning the refractive index of 
xerogel, well-refined in-plane birefrigency of some types of porous silicon [25, 26], drastic narrowing of the PL band in porous silicon microcavities [27, 28], strong PL of amorphous films with embedded silicon nanocrystals [29], biomedical application of porous silicon powder [30] could further stimulate development of the structures xerogel/porous silicon towards low-cost silicon-based optical materials.

Probably, relatively thick xerogel films, whose thickness is determined by the penetration depth of xerogel through the mesoscopic channels of the pores, enhanced by spinning, is not the single reason for the reported strong PL of lanthanides. Eu-implanted porous GaN film shows much stronger luminescence when compared to Eu-implanted as-grown GaN film [31]. Er implantation in porous $\mathrm{Si}$ gives higher photoluminescence intensity compared to Er-implanted bulk Si [17]. Enhancement of Er-related PL was observed when erbium implanted monocrystalline silicon had been transferred to porous silicon [32]. These and other experimental data lead to conclusion that multiple scattering of the exciting light in porous matrices, containing trivalent lanthanides, enhances their luminescence. Light scattering is even more significant for excitation in the matrices with periodically distributed mesoscopic pores like PAA.

\section{Porous anodic alumina}

Porous anodic alumina is known to exhibit a regular pore morphology with pores at the center of approximately hexagonal cells, whose size can be tailored $[33,34]$. Illustration of the possibility of tailoring the size of the cells by choosing the electrolyte and anodizing conditions is given by Fig. 2, which bring together selected scanning electron microscopy (SEM)-images of our PAA samples taken at the same magnification 40000 (a,b,c,d) or 60000 (e,f,g,h).

Transmission of PAA film within the wide visible and near IR spectral range could be greater than $90 \%$ at direction parallel to the pore channels and increases with perfection of the structure due to diminishing diffuse scattering on the defects of samples. Example of PAA membrane is given by Fig. 3. Transmission of PAA film drastically reduces even with slight deviation of the angle of incidence (registration) from direction parallel to the channels of the pores (Fig. 4a). This feature is considered regarding anisotropy of the photonic density of states (DOS) in mesoscopic structures with periodically modulated refractive index in 2 dimensions - 2D photonic crystals [35]. Anisotropy of DOS in PAA is well refined from the scattering measurement (Fig. 4b). Three petals are always observed at scattering indicatrixes measured for different angles of incidence. The one-side petal coincides with incident beam propagation, whereas orientation of the other-side petal shows mirror symmetry to incident beam with respect to the pore axis. Significant is appearance of the central petal along the channels of the pores regardless the angle of incidence. This central petal originates from diffuse scattering of light through the matrix with nonisotropic DOS like PAA film. DOS has a maximum value in the direction along the pores of anodic alumina films and a minimum in the perpendicular directions. 

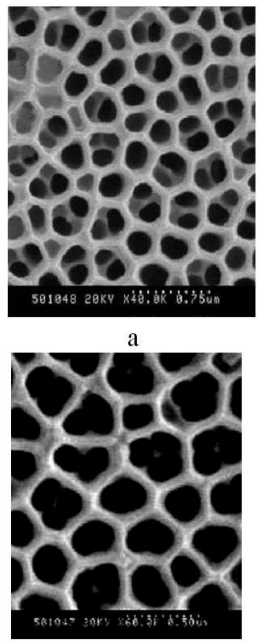

e
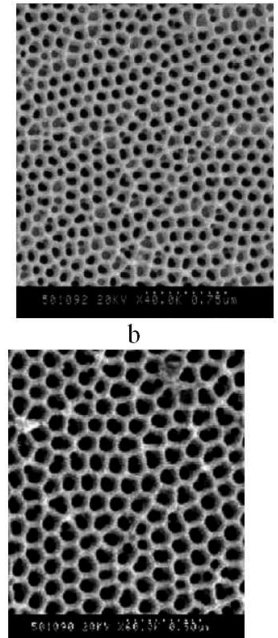
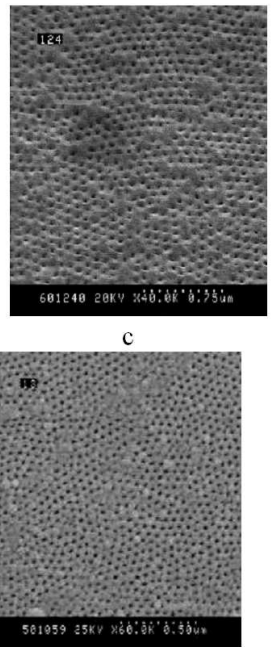

g
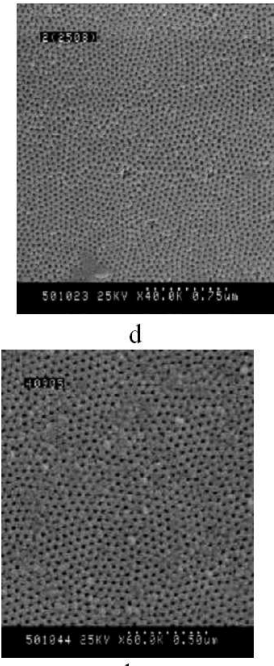

$\mathrm{h}$

Fig. 2. SEM-images of PAA films illustrating variation in size of the honey-comb cells and diameter of the pores. The images were selected for magnification 40000 (a, b, c, d) and 60000 (e, f, g, h). The samples were prepared at different electrolytes: (a) phosphoric acid 1.7\%, (b) oxalic acid 3\%, (c) sulphosalicylic acid 17\%, (d) sulphuric acid 9\%, (e) phosphoric acid $0.85 \%$, (f) oxalic acid $0.4 \%$, (g) phosphoric acid $9 \%+$ oxalic acid $5 \%,(\mathrm{~h})$ sulphuric acid $10 \%$.

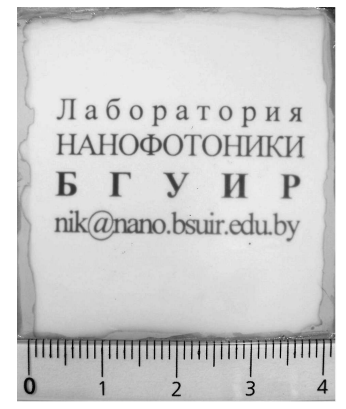

Fig. 3. Photograph of PAA membrane $4 \times 4 \mathrm{~cm}$ in size and about $100 \mu \mathrm{m}$ thick. In order to reveal its high transparence, the membrane was put onto a sheet of a white paper with the printed name of laboratory in Russian and the author's email address.

High-transparency of anodic alumina oxide on the one hand and strong optical anisotropy on the other hand may be the reasons of growing interest to exploit this material as a cage for light-emitting species. Filling the channels of the pores of anodic alumina films with silica [36-38], titania [23, 39-42], alumina [43-45] xerogels doped with lanthanide ions $\operatorname{Er}[37-39], \mathrm{Tb}[23,38,44]$ and $\mathrm{Eu}[35$, 40-42, 45], organic dyes [46], semiconductor nanocrystals [47, 48], polymers 


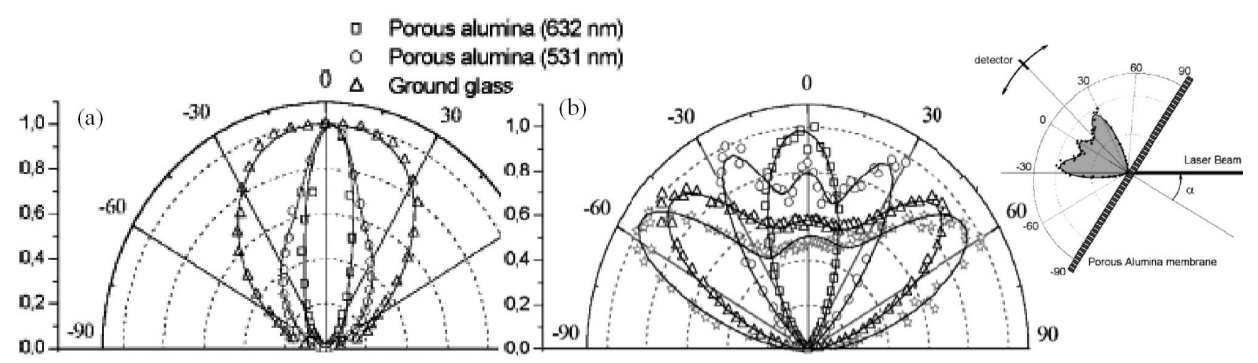

Fig. 4. Angular diagrams of the porous anodic alumina membrane: (a) transmission angular diagram and diagram of glass given for comparison; (b) scattering indicatrixes for different angles of laser beam incidence. Inset of Fig. 4b depicts scheme of experimental setup. Laser beam wavelength 632 and $531 \mathrm{~nm}$ (a), $632 \mathrm{~nm}$ (b), after Ref. [35].

$[49,50]$, quantum dots [51, 52], and biological samples [53] was investigated, and strong luminescence of optically active species incorporated in voids of anodic alumina or, probably, in its walls [54, 55] was reported.

Quantum dots like CdSe/ZnS core/shell could be embedded in free-standing porous alumina membrane by simply dipping, if the channels of the pores are opened from both sides by etching the residual aluminium and complete removing a barrier layer as well [51]. However, deposition of the sols and even suspension of semiconductive nanoparticles [56] or quantum dots [52] by spinning promotes their penetration deep into the pore volume even if the channels of the pores are opened from the top only, like for the PAA films fabricated on aluminium, silicon, quartz, or other substrates.

To investigate the spatial distribution of xerogel deposited onto PAA by spinning followed by thermal treatment, selected samples containing terbium-doped titania and alumina xerogels were examined by SIMS [37-39], transmission electron microscopy (TEM), SEM and energy distribution of X-ray (EDX) analyses $[23,40,41]$. After the first spin-on deposition of a sol followed by drying transmission electron micrographs revealed relatively dark, fine textured material of amorphous appearance at the base of the pore. Gel material towards the middle of the film appeared to be limited to a thin film on the surface of the cell material adjacent to the pores with the main parts of the pore volumes remaining unfilled. Further, the base of the pore $30 \mu \mathrm{m}$ thick is completely filled with the microporous alumina xerogel after five sequential spin-on depositions.

Technological methods of increase in the PL intensity through electrochemistry and sol-gel synthesis is given in Fig. 5. Er, Tb, and Eu luminescence from xerogels fabricated by spinning on PAA is much stronger than from the same xerogels fabricated on flat silicon substrate $[23,45,56-59]$. Because of the low efficiency of Er PL, fabrication of one spin-on layer is not sufficient for registration $1.54 \mu \mathrm{m}$ light emission $[8,22]$. Generally, PL of lanthanides from the structure xerogel/PAA increases with the thickness of PAA and for some excitation wave- 


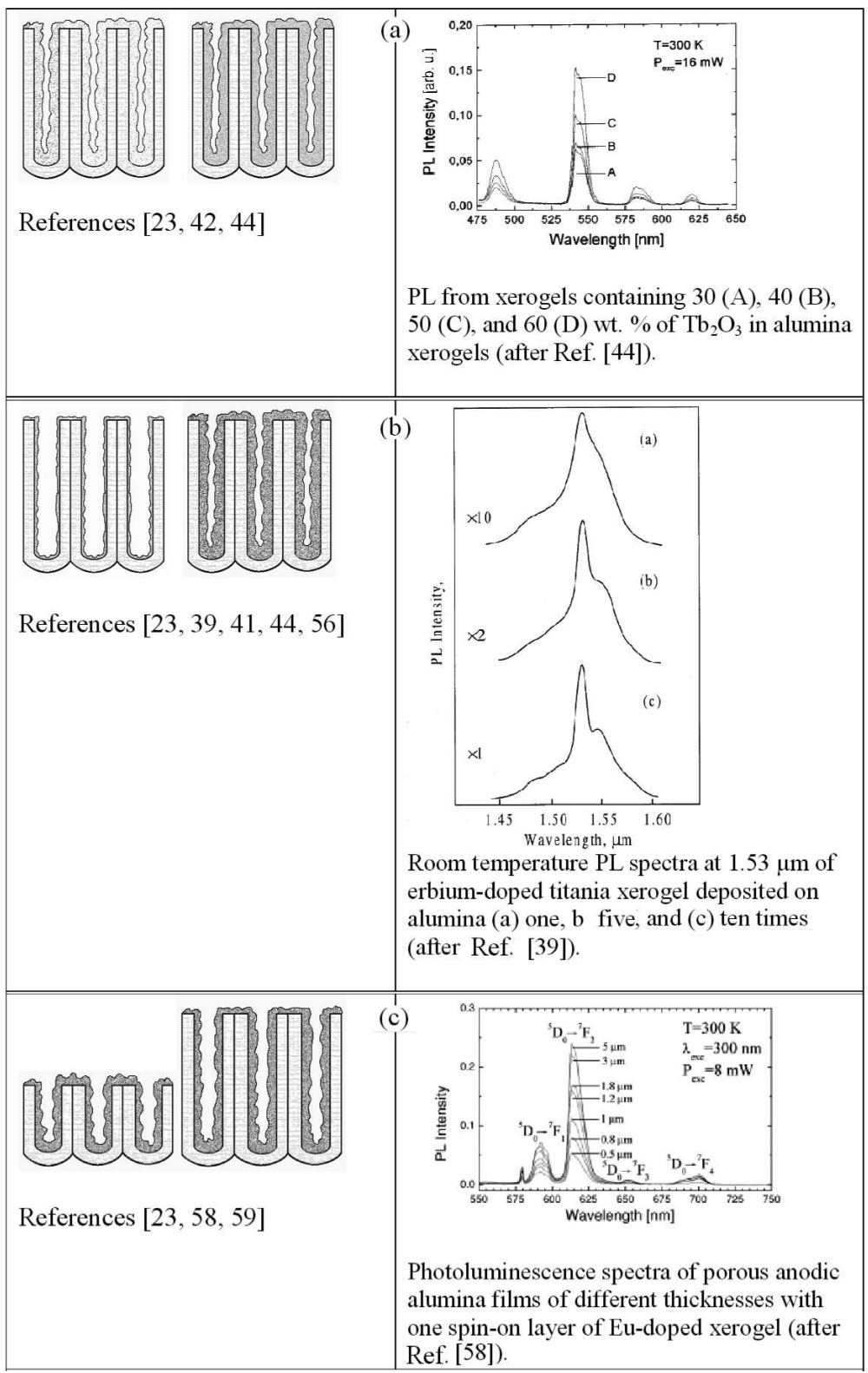

Fig. 5. Technological factors towards increase in PL of lanthanides from xerogel/porous anodic alumina structure: (a) increase in the concentration of lanthanides in xerogel; (b) increase in the number of xerogel layers; (c) increase in the porous $\mathrm{Al}_{2} \mathrm{O}_{3}$ film thickness.

length increases with the number of xerogel layers inside the pores $[41,56]$, and even with the chosen concentration of lanthanides in xerogels [23, 42, 59]. Con- 
centration quenching of lanthanides in xerogels embedded in mesoporous matrices has not been detected. Synthesis of the sols containing at least a precursor and dissolved salts of lanthanides assumes certain concentration of precursor in a sol to be deposited by spinning or dipping. In other words, concentration of salts of lanthanides in a sol and, accordingly, lanthanides in a xerogel could not be increased unlimitedly in a coatable solution. However, sol-gel derived films, doped with $\mathrm{Er}, \mathrm{Tb}$, or Eu did not reveal strong concentration quenching. Xerogel films fabricated by spinning a sol comprising metalloorganic precursors and alcoholic solvent contains a lot of uncontaminated carbon and other residual components, whose content, besides other factors, depends on the heating history, which in turn make influence on compromise between the elimination of organic groups of solvent and precursor and sintering of the micropores [1, 60]. For this reason atomic concentration of lanthanides in xerogels is often estimated in a molar percent or weight percent with respect to other oxide phases of xerogel. The optimum content of lanthanides oxide fit the range 30-40 wt.\% of $\mathrm{Ln}_{2} \mathrm{O}_{3}$ where $\mathrm{Ln}-\mathrm{Er}$, $\mathrm{Tb}$ or Eu, and accordingly the residual 70-60 wt.\% of film consists of the oxide derived from metalloorganic precursors $\mathrm{Me}_{x} \mathrm{O}_{y}\left(\mathrm{SiO}_{2}, \mathrm{TiO}_{2}, \mathrm{Al}_{2} \mathrm{O}_{3}\right.$, and other). These concentrations of lanthanide oxides correspond to several atomic percent of lanthanides in a film $\mathrm{Ln} /\left(\mathrm{Ln}+\mathrm{Me}+\mathrm{O}_{2}\right)$. Thus strong room-temperature luminescence of lanthanides with the concentration 30-40 wt. $\%$ of $\operatorname{Er}_{2} \mathrm{O}_{3}, \mathrm{~Tb}_{2} \mathrm{O}_{3}, \mathrm{Eu}_{2} \mathrm{O}_{3}$ was reported for $\mathrm{SiO}_{2}, \mathrm{TiO}_{2}, \mathrm{Al}_{2} \mathrm{O}_{3}, \mathrm{SiO}_{2} / \mathrm{TiO}_{2}$ films fabricated by spinning on PAA, whereas application of lower concentrations of lanthanides result in lower PL intensity. Decrease in PL intensity was observed in titania xerogel for $\mathrm{Tb}: \mathrm{Ti}$ molar ratio above $9.5 \%$ [61].

Some PAA samples fabricated in oxalic acid exhibit blue PL visible to the naked eye with a strong band at about $450 \mathrm{~nm}[52,62-64]$. The origin of the blue $\mathrm{PL}$ from PAA grown in oxalic acid is associated with generation of F-centres during anodizing of aluminium or excitation of residual chemical components absorbed from the electrolytes.

A method for the fabrication of luminescent visible images based on anodizing of aluminium, photolithography and sol-gel synthesis of Tb- and Eu-doped xerogels was recently proposed [65]. Development of multicolor luminescent images with the use of blue PL of PAA, light emission of quantum dots, lanthanides and also dye molecules $[66,67]$ from xerogels in PAA needs further experimental work. In addition to photoluminescent images revealing strong light emission at direction along the channels of the pores it is also attractive to aim recently reported sol-gel synthesis of X-ray phosphors [68, 69] for development light transformers on the basis of matrices with the spatial anisotropy of DOS like PAA.

\section{Artificial opals}

Multiple scattering of light by monodisperse spherical particles comprising artificial opals results in observation of photonic band gap [70]. Transmission spectra of artificial opals reveal a pronounced dip in the visible range corresponding to 
the lowest density of photonic states in photonic band gap structures. Photonic band-gap position of opals is shifted by changing the value of refractive index of interglobule spacing, that is accomplished by simply impregnation of the opal by dipping in liquids with diverse value of refractive index (Fig. 6a). Sol-gel synthesis
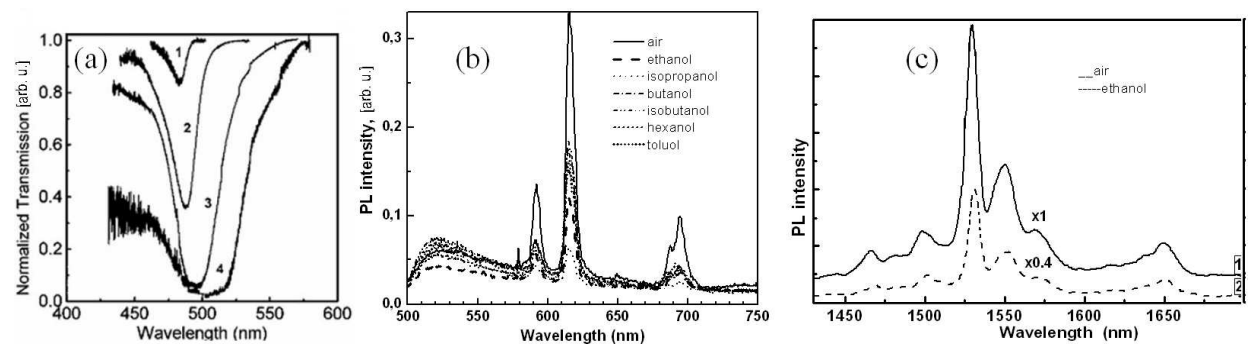

Fig. 6. Transmission (a) and PL (b, c) spectra of bare opals the embedded $\mathrm{TiO}_{2}$ xerogels doped with Eu or Er, recorded in air or in liquids: (a) transmission spectra of opals, indicating change in photonic band-gap for the same sample immersed in methanol (1), ethanol (2), cyclohexane (3), toluene (4), after Ref. [70]; (b) comparison of PL intensity from Eu-doped titania xerogel/opal in air and in liquids, $\lambda_{e x}=380 \mathrm{~nm}$; (c) comparison of PL intensity from Eu-doped titania xerogel/opal in air and in ethanol, $\lambda_{\text {ex }}=360 \mathrm{~nm}$.

of xerogels doped with lanthanides inside partial volume of interglobule spacing results in achievement of $3 \mathrm{D}$ photonic crystals doped with the lanthanides remaining with unfilled the residual part of volume [71]. Excitation of lanthanides in the structures based on artificial opals had been studied and modification of Eu [72], $\mathrm{Tb}[73,74]$, and $\operatorname{Er}[75,76]$ luminescence characteristics was reported. Our recent experiments reveal strong dependence of $\mathrm{Er}$ and $\mathrm{Eu}$ PL intensity on refractive index of liquids inside the voids of the samples of artificial opal/titania xerogel, doped with erbium or europium (Fig. 6b,c). One of the reason of the observed dependence, which is reproducible and reversible for the wet and dried samples of xerogel/opal, is supposed to be influenced by light scattering on lanthanides excitations in mesoscopic structures. The observed modification of Er photoluminescence excitation spectrum (PLE) for the emission wavelength $1.54 \mu \mathrm{m}$ manifested by appearance of a strong band at $360 \mathrm{~nm}$ for the structure opal/titania xerogel $[75,76]$, results from favourable interaction between silica and titania [77]. The strong PLE band in ultraviolet range obtained for the $\mathrm{TiO}_{2} / \mathrm{SiO}_{2}$ composites makes, from our point of view, these materials attractive for the development of light transformers for the rapidly extended market of short-wavelength optoelectronic devices on the basis of the group III nitrates [78, 79].

\section{Conclusions}

In conclusion, penetration of sols containing lanthanide ions through mesoscopic channels of porous silicon, PAA and artificial opals followed by thermal 
treatment, promotes strong photoluminescence of lanthanides. The structures reveal low PL concentration quenching. One of the reason of enhanced photoluminescence observed from PAA is supposed to be the anisotropy of DOS. PL intensity of lanthanides in photonic crystals is sensitive to scattering conditions and could be adjusted by filling the volume of mesoscopic pores with diverse liquids.

\section{Acknowledgments}

Most of the samples described in the paper were prepared in Laboratory of Nanophotonics, BSUIR, organized by Prof. V.E. Borisenko, by I.S. Molchan, O.V. Sergeev, E.A. Stepanova, G.K. Maliarevich, T.I. Orekhovskaja, D.A. Tsyrkunov. The author also appreciates fruitful cooperation with the groups of Professors B. Hamilton, G.E. Thompson (UK), J. Misiewicz, W. Strȩk (Poland), S.V. Gaponenko, A.V. Mudryi (Belarus), M.N. Popova, M.I. Samoilovich, Z.F. Krasilnik (Russia), H. Oechsner, M.A. Aegerter, L.J. Balk (Germany), L. Palmetshofer, W. Jantsch (Austria), Drs. M. Stepikhova (Russia), V. Lambertini, P. Repetto and P. Perlo (Italy), J.C. Pivin (France).

\section{References}

[1] L.L. Hench, J.K. West, Chem. Rev. 90, 33 (1990).

[2] Porous Silicon Science and Technology, Eds. J.-C. Vial, J. Derrien, Springer-Verlag, Les Editions de Physique, Les Ulis 1995, p. 356.

[3] A.G. Cullis, L.T. Canham, P.D.J. Calcott, J. Appl. Phys. 82, 909 (1997).

[4] A. Uhlir, Bell Syst. Tech. J. 35, 333 (1956).

[5] D.R. Turner, J. Electrochem. Soc. 105, 402 (1958).

[6] L.T. Canham, Appl. Phys. Lett. 57, 1046 (1990).

[7] M. Stepikhova, L. Palmetshofer, W. Jantsch, H.J. von Bardeleben, N.V. Gaponenko, Appl. Phys. Lett. 74, 537 (1999).

[8] A.M. Dorofeev, N.V. Gaponenko, V.P. Bondarenko, E.E. Bachilo, N.M. Kazuchits, A.A. Leshok, G.N. Troyanova, N.N. Vorozov, V.E. Borisenko, H. Gnaser, W. Bock, P. Becker, H. Oechsner, J. Appl. Phys. 77, 2679 (1995).

[9] A. Dorofeev, E. Bachilo, V. Bondarenko, V. Borisenko, N. Gaponenko, N. Kazuchits, G. Troyanova, N. Vorosov, H. Gnaser, W. Bock, P. Becker, H. Oechsner, Thin Solid Films 276, 171 (1996).

[10] S. Sen, J. Siejka, A. Savtchouk, J. Lagowski, Appl. Phys. Lett. 70, 2253 (1997).

[11] N.V. Gaponenko, A.V. Mudryi, O.V. Sergeev, V.E. Borisenko, E.A. Stepanova, A.S. Baran, A.I. Rat'ko, J.C. Pivin, J.F. McGilp, Phys. Status Solidi A 165, 131 (1998).

[12] W. Henley, Y. Koshka, J. Lagowski, J. Siejka, J. Appl. Phys. 87, 7848 (2000).

[13] A. Moadhen, H. Elhouichet, S. Romdhane, M. Questati, J.A. Roger, H. Bouchriha, Semicond. Sci. Technol. 18, 703 (2003).

[14] A. Moadhen, H. Elhouichet, C. Jardin, M. Questati, J.A. Roger, Phys. Status Solidi A 202, 1508 (2005). 
[15] N.V. Gaponenko, A.V. Mudryi, O.V. Sergeev, M. Stepikhova, L. Palmetshofer, W. Jantsch, J.C. Pivin, B. Hamilton, A.S. Baran, A.I. Rat'ko, J. Lumin. 80, 399 (1999).

[16] H. Elhouichet, A. Moadhen, M. Questati, M. Ferid, J. Lumin. 97, 34 (2002).

[17] F. Namavar, F. Lu, C.H. Perry, A. Cremins, N.M. Kalkhoran, R.A. Soref, J. Appl. Phys. 77, 4813 (1995).

[18] A. Polman, J. Appl. Phys. 82, 1 (1997).

[19] T. Kimura, A. Yokoi, H. Horiguchi, R. Saito, T. Ikoma, A. Sato, Appl. Phys. Lett. 65, 983 (1994).

[20] H.A. Lopez, P.M. Fauchet, Phys. Status Solidi A 182, 413 (2000).

[21] M. Stepikhova, W. Jantsch, G. Kocher, I. Palmetshofer, M. Schoisswohl, H.J. von Bardeleben, Appl. Phys. Lett. 71, 2975 (1997).

[22] C.K. Rui, H. Choi, K. Kim, Appl. Phys. Lett. 66, 2496 (1995).

[23] N.V. Gaponenko, J.A. Davidson, B. Hamilton, P. Skeldon, G.E. Thompson, X. Zhou, J.C. Pivin, Appl. Phys. Lett. 76, 1006 (2000).

[24] N.A. Drozdov, A.A. Patrin, V.D. Tkachev, Sov. Phys. JETP Lett. 23, 597 (1996).

[25] N. Kuenzner, D. Kovalev, J. Diener, E. Gross, V.Yu. Timoshenko, G. Polisski, F. Koch, M. Fujii, Opt. Lett. 26, 1265 (2001).

[26] V.Yu. Timoshenko, L.A. Osminkina, A.I. Efimova, L.A. Golovan, P.K. Kashkarov, Phys. Rev. B 67, 113405 (2003).

[27] L. Pavesi, Phys. Status Solidi A 165, 91 (1998).

[28] H.A. Lopez, P.M. Fauchet, Mater. Sci. Eng. B 81, 91 (2001).

[29] S. Gardelis, I. Tsiaoussis, N. Frangis, A.G. Nassiopoulou, Nanotechnology 18, 115705 (2007).

[30] V.Yu. Timoshenko, A.A. Kudryavtsev, L.A. Osminkina, A.S. Vorontsov, Yu.V. Ryabchikov, I.A. Belogorokhov, D. Kovalev, P.K. Kashkarov, JETP Lett. 83, 423 (2006).

[31] A.P. Vajpeyi, S. Tripathy, L.S. Wang, B.C. Foo, S.J. Chua, E.A. Fitzgerald, E. Alves, J. Appl. Phys. 99, 104305 (2006).

[32] T. Taskin, S. Gardelis, J.H. Evans, B. Hamilton, A.R. Peaker, Electr. Lett. 31, 2132 (1995).

[33] G.E. Thompson, R.C. Furneaux, G.C. Wood, J.A. Richardson, J.S. Goode, Nature 272, 433 (1978).

[34] G.E. Thompson, G.C. Wood, Nature (London) 290, 231 (1981).

[35] A.A. Lutich, S.V. Gaponenko, N.V. Gaponenko, I.S. Molchan, V.A. Sokol, V. Parkhutik, Nano Lett. 4, 1755 (2004).

[36] N.V. Gaponenko, V.M. Parkun, E.E. Bachilo, G.E. Malashkevich, V.E. Borisenko, in: Physics, Chemistry and Application of Nanostructures: Reviews and Short Notes to NANOMEETING'95 1995, Eds. V.E. Borisenko, A.B. Filonov, S.V. Gaponenko, V.S. Gurin, BSUIR, Minsk 1995, p. 80.

[37] N.V. Gaponenko, A.V. Mudryi, V.M. Parkun, E.A. Stepanova, A.I. Ratko, V.E. Borisenko, Inorg. Mater. 33, 916 (1997). 
[38] N.V. Gaponenko, V.M. Parkun, O.S. Katernoga, V.E. Borisenko, A.V. Mudryi, E.A. Stepanova, A.I. Rat'ko, M. Cavanagh, B. O'Kelly, J.F. McGilp, Thin Solid Films 297, 202 (1997).

[39] N.V. Gaponenko, O.V. Sergeev, E.A. Stepanova, V.M. Parkun, A.V. Mudryi, H. Gnaser, J. Misiewicz, R. Heiderhoff, L.J. Balk, G.E. Thompson, J. Electrochem. Soc. 148, H13 (2001).

[40] N.V. Gaponenko, I.S. Molchan, G.E. Thompson, P. Skeldon, A. Pakes, R. Kudrawiec, L. Bryja, J. Misiewicz, Sensors Actuators A 99, 71 (2002).

[41] I.S. Molchan, N.V. Gaponenko, R. Kudrawiec, J. Misiewicz, G.E. Thompson, P. Skeldon, J. Electrochem. Soc. 151, H16 (2004).

[42] A. Peng, E. Xie, C. Jia, R. Jiang, H. Lin, Mater. Lett. 59, 3866 (2005).

[43] N.V. Gaponenko, A.V. Mudryi, O.V. Sergeev, V.E. Borisenko, E.A. Stepanova, A.S. Baran, A.I. Rat'ko, J.C. Pivin, J.F. McGilp, Spectrochim. Acta A 54, 2177 (1998).

[44] N.V. Gaponenko, I.S. Molchan, O.V. Sergeev, G.E. Thompson, A. Pakes, P. Skeldon, R. Kudrawiec, L. Bryja, J. Misiewicz, J.C. Pivin, B. Hamilton, E.A. Stepanova, J. Electrochem. Soc. 149, H49 (2002).

[45] R. Kudrawiec, A. Podhorodecki, N. Mirowska, J. Misiewicz, I. Molchan, N.V. Gaponenko, A.A. Lutich, S.V. Gaponenko, Mater. Sci. Eng. B 105, 53 (2003).

[46] A. Moadhen, H. Elhouichet, L. Nosova, M. Oueslati, J. Lumin. 126, 789 (2007).

[47] V.S. Dneprovski, E.A. Zhukov, O.A. Shalygina, V.L. Lyaskovski, E.A. Muljarov, S.A. Gavrilov, Y. Masumoto, J. Exp. Theor. Phys. 94, 1169 (2002).

[48] A.I. Belogorokhov, S.A. Gavrilov, L.I. Belogorokhova, Phys. Status Solidi A 197, 204 (2003).

[49] D. Qi, K. Kwong, K. Rademacher, M.O. Wolf, J.F. Young, Nano Lett. 3, 1265 (2003).

[50] Y. Shen, R. Jia, H. Luo, X. Chen, D. Xue, Z. Hu, Spectrochim. Acta A 60, 1007 (2004).

[51] J. Xu, J. Xia, J. Wang, J. Shinar, Z. Lin, Appl. Phys. Lett. 89, 133110 (2006).

[52] N.V. Gaponenko, T.I. Orehovskaya, G.K. Maliarevich, D.A. Tsyrkunov, I.S. Molchan, G.E. Thompson, in: Physics, Chemistry and Applications of Nanostructures: Reviews and Short notes to NANOMEETING-200\%, Eds. V.E. Borisenko, S.V. Gaponenko, V.S. Gurin, World Scientific, Singapore 2007, p. 570.

[53] V. Grasso, V. Lambertini, P. Ghisellini, F. Valerio, E. Stura, P. Perlo, C. Nicolini, Nanotechnology 17, 795 (2006).

[54] S.K. Lazarouk, A.V. Mudryi, V.E. Borisenko, Appl. Phys. Lett. 73, 2272 (1998).

[55] T. Li, S. Yang, L. Huang, J. Zhang, B. Gu, Y. Du, J. Phys., Condens. Matter 16, 2463 (2004).

[56] N.V. Gaponenko, I.S. Molchan, D.A. Tsyrkunov, G.K. Maliarevich, M. Aegerter, J. Puetz, N. Al-Dahoudi, J. Misiewicz, R. Kudrawiec, V. Lambertini, N. Li Pira, P. Repetto, Microelectron. Eng. 81, 255 (2005).

[57] I.S. Molchan, N.V. Gaponenko, R. Kudrawiec, J. Misiewicz, G.E. Thompson, Mater. Sci. Eng. B 105, 37 (2003). 
[58] R. Kudrawiec, J. Misiewicz, L. Bryja, I.S. Molchan, N.V. Gaponenko, J. Alloys Comp. 341, 211 (2002).

[59] I.S. Molchan, N.V. Gaponenko, R. Kudrawiec, J. Misiewicz, L. Bryja, G.E. Thompson, P. Skeldon, J. Alloys Comp. 341, 251 (2002).

[60] N.V. Gaponenko, H. Gnaser, P. Becker, V.A. Grozhik, Thin Solid Films 261, 186 (1995).

[61] E. Xie, C. Jia, A. Peng, R. Jiang, F. Ye, H. Lin,T. Xu, Thin Solid Films 496, 555 (2006)

[62] G.H. Li, Y. Zhang, Y.C. Wu, L.D. Zhang, J. Phys., Condens. Matter 15, 8663 (2003).

[63] W.L. Xu, M.J. Zheng, S. Wu, W.Z. Shen, Appl. Phys. Lett. 85, 4364 (2004).

[64] G.H. Li, Y. Zhang, Y.C. Wu, L.D. Zhang, Appl. Phys. A 81, 627 (2005).

[65] N.V. Gaponenko, I.S. Molchan, G.E. Thompson, V. Lambertini, P. Repetto, J. Soc. Information Display 11, 27 (2003).

[66] K. Maruszewski, D. Andrzejewski, W. Strek, J. Lumin. 72-74, 226 (1997).

[67] K. Maruszewski, M. Jasiorski, M. Salamon, W. Strȩk, Chem. Phys. Lett. 314, 83 (1999).

[68] E. Zych, P.J. Deren, W. Strȩk, A. Meijerink, W. Mielcarek, K.J. Domagala, J. Alloys Comp. 323-324, 8 (2001).

[69] W. Strȩk, E. Zych, D. Hreniak, J. Alloys Comp. 344, 332 (2002).

[70] V.N. Bogomolov, S.V. Gaponenko, I.N. Germanenko, A.M. Kapitonov, E.P. Petrov, N.V. Gaponenko, A.V. Prokofiev, A.N. Ponyavina, N.I. Silvanovich, S.M. Samoilovich, Phys. Rev. E 55, 7619 (1997).

[71] A.M. Kapitonov, N.V. Gaponenko, V.N. Bogomolov, A.V. Prokofiev, S.M. Samoilovich, S.V. Gaponenko, Phys. Stat. Sol. A 165, 119 (1998).

[72] S.G. Romanov, A.V. Fokin, R.M. De La Rue, Appl. Phys. Lett. 76, 1656 (2000).

[73] N.V. Gaponenko, Synthetic Metals 124, 125 (2001).

[74] M. Aloshyna, S. Sivakumar, M. Venkataramanan, A.G. Brolo, F.C.J.M. van Veggel, J. Phys. Chem. C 111, 4047 (2007).

[75] N.V. Gaponenko, D.M. Unuchak, A.V. Mudryi, G.K. Malyarevich, O.B. Gusev, M.V. Stepikhova, L.V. Krasilnikova, A.P. Stupak, S.M. Kleshcheva, M.I. Samoilovich, M.Yu. Tsvetkov, J. Lumin. 121, 217 (2006).

[76] N.V. Gaponenko, G.K. Maliarevich, A.V. Mudryi, O.B. Gusev, M.V. Stepikhova, M.Yu. Tsvetkov, S.M. Kleshcheva, M.I. Samoilovich, A.P. Stupak, J. Appl. Spectrosc. 74, 622 (2007).

[77] R.J. Davis, Z. Liu, Chem. Mater. 9, 2311 (1997).

[78] O. Ambacher, J. Phys. D 31, 2653 (1998).

[79] J.W. Orton, C.T. Foxon, Rep. Prog. Phys. 61, 1 (1998). 